\title{
Motivation and performance in skill and chance defined situations ${ }^{1}$
}

ROBERT A. BARON

UNIVERSITY OF IOWA

It was hypothesized that a higher level of motivation would be induced among $S$ s by instructions which defined a given situation as skill controlled than by instructions which defined the same situation as chance controlled. In order to test this hypothesis a situation in which $S s^{\prime}$ dominant responses were reinforced was employed. Results indicated that skill instructed Ss made significantly more correct responses than chance instructed Ss under these conditions.

Rotter (1966) has suggested that reinforcement may have a greater effect upon behavior when an individual perceives that he can control the reinforcements he receives than when he perceives that they are beyond his control. Rotter has sought to explain this differential effectiveness of reinforcement in situations perceived by Ss as skill (internally) or chance (externally) controlled within the context of social learning theory (Rotter, 1954). However, it may also be explained within the framework of general behavior theory (Hull, 1952; Brown, 1961) If it is assumed that a higher level of motivation is induced among $S$ s when they define a given situation as skill controlled than when they define the same situation as chance controlled. The present experiment was designed to test this hypothesis by observing the performance of skill and chance instructed Ss in a situation where Ss' dominant responses were reinforced. It was predicted that under these conditions, skill instructed Ss would show a faster rise to a higher final level of performance than chance instructed Ss.

Method

Twenty-six male undergraduates enrolled in courses in psychology at the University of Iowa participated in the experiment. The apparatus consisted of a Kodak Carousel slide projector, two $35 \mathrm{~mm}$ slides, 50 Unknown Alternative cards, and Score Sheets. The slides contained a typed +1 or -1 . The Unknown Alternative cards consisted of $503 \times 5$ in. index cards on each of which was typed a number from -2 to -6 , or +2 to +6 . The Score Sheets contained 100 numbered spaces. The task was an adaptation of procedures employed by Myers \& Sadler (1960). The two slides were presented to all $\mathrm{Ss}$ in the same fixed order. Each time a slide was shown $\mathrm{S}$ was asked to decide if he wished to accept the outcome shown on that slide (i.e., win or lose one point), or one of the Unknown Alternative cards instead. The $S$ signalled his decisions by saying "card" or "slide." He then entered the outcome shown on the slide (if he accepted this result), or a check mark (if he accepted an Unknown Alternative card), in the appropriate space on the Score Sheet. It was explained that at the end of the series of slides $S$ could turn over one Unknown Alternative card for each check mark he had made, and thus determine his results on trials where he had said "card." After S made his decision about each slide, E informed him if it was "right" or "wrong." The $\mathrm{S}$ was told that E would say "right" if S's decision resulted in his winning more points than he would have won by making the opposite decision, and that $E$ would say "wrong" If S's decision resulted in his losing more points than he would have lost by making the opposite decision. Actually, during the first 70 trials $E$ said "right" (i.e., administered reinforcement) each time $S$ said "slide" when a +1 was shown, or "card" when a -1 was shown. A previous experiment (Myers \& Sadler, 1960) has shown that these are the dominant responses in this situation. The E said "wrong" (i.e., administered punishment) to all other responses. Counter conditioning procedures were begun on Trial 71. From that point on $E$ reinforced responses previously punished and punished responses previously reinforced.

After completion of the general instructions, and before $\mathrm{S}$ began responding, special skill, chance, and partial control instructions were read. The skill control instructions stated that S's outcomes were determined by skill and were under his own control. The chance control instructions stated that S's outcomes were determined by chance and were not under his control. The partial control instructions stated that S's outcomes were determined both by skill and chance and were partially under his control. Results

The mean number of responses classified as correct during acquisition made by Ss in the skill (SC), chance (CC), and partial control (PC) groups during both phases of the experiment are presented in Fig. 1.

Considering acquisition, it can be seen that the SC and PC groups maintained a higher level of performance than the CC group in all blocks of trials. A Type I analysis of variance (Lindquist, 1952) performed on the number of correct responses indicated that there were significant effects for instructions $(F=5.54, \mathrm{df}=2 / 23, \mathrm{p}<.05)$ and for trials $(F=20.83$, $\mathrm{df}=6 / 138, \mathrm{p}<.001$ ). The interaction between these two factors was not significant $(F=.37, \mathrm{df}=12 / 138$, $p>.20$ ), thus indicating that all groups showed approximately equal rates of improvement over trials. To examine the significant effect of instructions more 


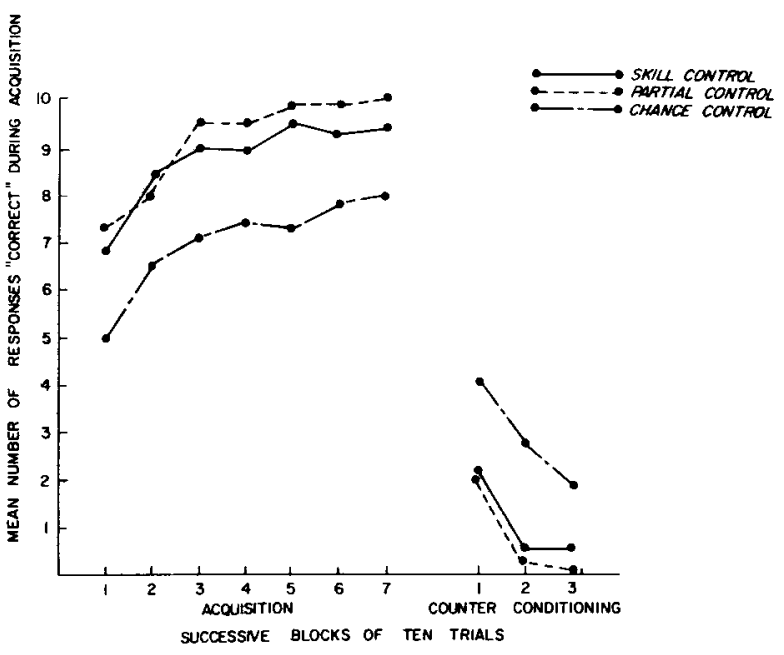

Fig. 1. Mean number of responses classified as correct during acquisition in blocks of trials.

closely, the mean number of correct responses made by the $\mathrm{PC}, \mathrm{SC}$, and $\mathrm{CC}$ groups during acquisition were compared by $t$ tests. The means for these groups were $9: 14,8.76$, and 7.01 , respectively. The means for the $\mathrm{CC}$ and $\mathrm{PC}$ groups were significantly different $(t=3.42, \mathrm{df}=14, \mathrm{p}<.01)$, as were those of the $\mathrm{CC}$ and SC groups $(t=2.54, \mathrm{df}=18, \mathrm{p}<.05)$. The means of the PC and SC groups did not differ significantly $(t=.92, \mathrm{df}=14, \mathrm{p}>.20)$. Thus, the CC group made significantly fewer correct responses during acquisition than did the PC and SC groups, but these latter groups did not differ significantly in this phase of the experiment.

Considering the counter conditioning, it can be seen that the order of the groups was reversed so that the $\mathrm{CC}$ group made more previously correct responses than the $\mathrm{SC}$ and $\mathrm{PC}$ groups in all blocks of trials. During this phase of the experiment such responses were classified as incorrect and will be referred to in this manner hereafter. A Type I anal$y$ sis of variance performed on the number of incorrect responses indicated that there were significant effects for instructions $(\mathrm{F}=4.09, \mathrm{df}=2 / 23, \mathrm{p}<.05)$ and for trials $(F=18.44$, df $=2 / 46, p<.001)$. The interaction between these two factors was not significant $(F=.29$, $\mathrm{df}=4 / 46, p>.20$ ). To examine the significant effect of instructions more closely, the mean number of incorrect responses made by the $\mathrm{PC}, \mathrm{SC}$, and $\mathrm{CC}$ groups during counter conditioning were compared by means of $t$ tests. The means for these groups were $.78,1.02$, and 2.87 , respectively. The means of the $\mathrm{CC}$ and $\mathrm{PC}$ groups were significantly different $(t=2.84, \mathrm{df}=14, \mathrm{p}<.05)$, as were those of the $\mathrm{CC}$ and SC groups $(t=2.26, d f=18, p<.05)$. The means of the $\mathrm{SC}$ and $\mathrm{PC}$ groups did not differ significantly $(t=.89, d f=14, p>.20)$. Thus, the $\mathrm{CC}$ group made significantly more incorrect responses during counter conditioning than did the $\mathrm{PC}$ and $\mathrm{SC}$ groups, but these latter groups did not differ significantly in this phase of the experiment.

\section{Discussion}

The hypothesis that the SC group would attain a higher level of performance than the CC group was confirmed. Ss in the SC group made more correct responses than $S s$ in the $C C$ group throughout the experiment. However, the hypothesis that the performance curves of these two groups would diverge over trials was not supported. One possible reason for this finding may have been the high levels of performance attained by the SC group very early in acquisition and counter conditioning. These levels of performance may have been so high as to preclude additional improvements over trials. Thus, ceiling effects may have prevented the occurrence of the predicted divergence.

One interesting result of the present experiment was the finding that the PC and SC groups performed at the same level throughout the experiment. This finding indicates that partial control instructions may produce motivational effects similar to those produced by skill control instructions.

The finding that $\mathrm{Ss}$ in the $\mathrm{PC}$ and $\mathrm{SC}$ groups made fewer incorrect responses during counter conditioning than $S s$ in the $\mathrm{CC}$ group would not have been predicted from the performance levels attained by these groups during acquisition. This result indicates that associative factors (e.g., greater attention to the reinforcement contingency by Ss in the SC and PC groups) may have played a role in the present situation. The possibility of such effects will be investigated in future research.

\section{References}

BROWN, J. S. The motivation of behavior. New York: McGraw-Hill, 1961.

HULL, C. L. A behavior system. New Haven: Yale University Press, 1952.

LINDQUIST, E. F. Design and analysis of experiments. Boston: Houghton Mifflin Co., 1953.

MYERS, J. L., \& SADLER, E. Effects of range of payoff as a variable in risk-taking. J. exp. Psychol., 1960, 60, 306-309.

ROTTER, J. B. Social learning and clinical psychology. New York: Prentice-Hall, 1954.

ROTTER, J, B. Generalized expectancies for internal versus external control of reinforcement. Psychol. Monogr., 1966, 80, 1, 609. Note

1. The author wishes to express his appreciation to Dr. P. Murdoch for his assistance in the preparation of this manuscript. 